\title{
A Case Study of Dexmedetomidine as an Intrathecal Adjuvant for Postoperative Analgesia in Orthopedic Lower Limb Surgeries
}

\author{
Dr. Athyun .G ${ }^{1}$, Dr. Malathi .C . $\mathbf{N}^{2}$, Dr. Nalini Kotekar ${ }^{3}$ \\ ${ }^{1}$ Post Graduate, Department Of Anesthesiology, JSS Medical College, MYSURU \\ ${ }^{2}$ MD. D.A, Professor, Department of Anesthesiology, JSS Medical College, MYSURU \\ ${ }^{3}$ MD. D.A, Professor and HOD, Department of Anesthesiology, JSS Medical College, MYSURU
}

\begin{abstract}
Background and Objective: Spinal anaesthesia is the most common approach which is used for lower limb surgery. Dexmedetomidine is the recent drug which acts on a2-adrenergic receptors in the dorsal horn of the spinal cord to produce analgesic effects. The aim is to check efficacy and safety of intrathecal Dexmedetomidine added to Ropivacaine. Postoperative cumulative analgesic consumption and maximum visual analogue scale (VAS) pain score have been evaluated as secondary outcome. Materials and Methods: With simple random sampling technique, 60 patients of either sex between age group of 18 to 60 yrs, ASA I or II, posted for lower limb orthopedic surgery under spinal anaesthesia were selected who fulfil the inclusion, exclusion criteria and divided them into two groups of 30 each. Results: Both absolute and effective analgesia durations were prolonged in Group RD with absolute analgesia duration being $350.33 \pm 59.49$ minutes in Group $R D$ as compared to $215.03 \pm 25.57$ minutes in Group $R(p<0.001)$, the difference being statistically highly significant. The duration of effective analgesia in Group RD was $490.83 \pm 38.73$ minutes as compared to $271.83 \pm 34.42$ minutes in Group $R(p<0.001)$. This difference was highly significant statistically. No postoperative complications were seen in either of thegroups. Conclusion: Mixture of Dexmedetomidine $5 \mu \mathrm{g}$ and Isobaric Ropivacaine $0.75 \%$ (22.5 mg) when given intrathecally influences the sensory and motor block by shortening the onset time and prolonging the duration of absolute and effective analgesia without affecting the other parameters and complications of subarachnoid block
\end{abstract}

Keywords: Dexmedetomidine, Ropivacaine, intrathecal, lower limb orthopedic, postoperative analgesia

\section{Introduction}

Despite tremendous advancements in the field of general anaesthesia, regional anaesthesia in the form of Central Neuraxial Blockade remains the most commonly used technique for lower limb orthopaedic surgeries. This is because of its well known advantages like -

- Preservation of consciousness

- Simple and easy to perform

- Adequate surgical anaesthesia

- Minimal interference with blood biochemistry

- Avoidance of complications of general anaesthesia.

Ropivacaine is a new long acting amide local anaesthetic agent, related structurally to Bupivacaine. It is developed as a pure S (-) enantiomer of Propivacaine. It is less lipophilic than Bupivacaine and is therefore less likely to produce neurotoxicity and cardiotoxicity. Moreover due to less lipophilicity it does not penetrate large myelinated motor fibers to a great extent resulting in a lesser degree of motor block. Thus, in today's time Ropivacaine seems to be a good alternative to Bupivacaine in situations where less degree of motor block is an advantage.

Dexmedetomidine is a highly selective $\alpha 2$-adrenoceptor agonist with a $\alpha 1: \alpha 2$ selectivity ratio of $1: 1620$ which is 8 times higher than that of Clonidine. Thus, the effects of Dexmedetomidine at clinically relevant concentrations are selectively mediated through $\alpha 2$-adrenoceptors.Use of intrathecal Dexmedetomidine, with local anaesthetics has shown that it shortens the onset time of sensory and motorblockade as well as prolongs the duration of sensory and motor blockade and postoperative analgesia without serious side effects.

Thus, we decided to take Dexmedetomidine as an adjuvant to intrathecal isobaric Ropivacaine for spinal anaesthesia in patient undergoing lower limb orthopedic surgeries.

\section{Literature Survey}

In a study conducted by Rajni Gupta, Jaishri Bogra et al, in which sixty patients were randomly allocated to receive intrathecally either $3 \mathrm{ml}$ of $0.75 \%$ isobaric Ropivacaine + $0.5 \mathrm{ml}$ normal saline (Group R) or $3 \mathrm{ml}$ of $0.75 \%$ isobaric Ropivacaine $+5 \mu \mathrm{g}$ Dexmedetomidine in $0.5 \mathrm{ml}$ of normal saline (Group D). The results show that addition of Dexmedetomidine to Ropivacaine intrathecally produces a prolongation in the duration of the motor and sensory block ${ }^{1}$.

Alka Shah, Ila Patel, Rachana Gandhi conducted a study with 50 patients of ASA I and II scheduled for lower limb and lower abdominal surgery were selected. Each patient received $4 \mathrm{ml}$ of $0.75 \%$ isobaric Ropivacaine +5 microgram Dexmedetomidine. The results showed that the combination of Ropivacaine and Dexmedetomidine provided better postoperative analgesia and reduced requirement of diclofenac injection in first 24 hours. The patients showed excellent hemodynamic stability and postoperative analgesia to Ropivacaine + Dexmedetomidine ${ }^{2}$.

\section{Volume 5 Issue 2, February 2016}




\section{International Journal of Science and Research (IJSR) \\ ISSN (Online): 2319-7064 \\ Index Copernicus Value (2013): 6.14 | Impact Factor (2014): 5.611}

Marie-Pier Malenfant Rancourt ,MD, Natalie T. Albert, MD et al, conducted study on 14 healthy volunteers were allocated to 2 groups. In group $\mathrm{R}, 10 \mathrm{~mL}$ of $0.5 \%$ ropivacaine was injected for the block; in group $\mathrm{RD}, 10 \mathrm{ml}$ of a solution containing $0.5 \%$ ropivacaine with $1 \mu \mathrm{g} / \mathrm{kg}$ of dexmedetomidine was administered. Results showed that dexmedetomidine added to ropivacaine for tibial nerve block prolongs the duration of sensory blockade with similar onset time $^{3}$.

\section{Materials and Methods}

The present study was carried out in department of Anesthesiology, JSS Medical College and Hospital, Mysuru as a randomized prospective clinical study of 60 patients from August 2013 to December 2014.

30 patients of either sex between age group of 18 to $60 \mathrm{yrs}$, ASA I or II,posted for lower limb orthopedic surgery under Spinal anaesthesia were taken in each group. Randomization was done with computer method.

By using the mean and standard deviation values derived in the main reference study "Dexmedetomidine as an intrathecal adjuvant for post operative analgesia"

Rajnigupta, Jaishribogra, Monickohli, Jitenderkumarkushawha and Sanjeevkumar. Indian $J$ Anaesth. Jul-Aug ;55(4):347-351. This study was conducted in adult patients of age 18 years and above undergoing orthopedic lower limb surgeries under spinal anaesthesia in JSS Hospital, Mysore. With simple random sampling technique, 60 patients were selected who fulfil the inclusion, exclusion criteria and divided them into two groups of 30 each.

Group RD (Dexmedetomidine group): Received intrathecalDexmedetomidine at dose of $5 \mathrm{mcg}$ in $0.5 \mathrm{ml}$ of normal saline with $3 \mathrm{ml}$ of $0.75 \%$ isobaric Ropivacaine.

Group R (Ropivacaine group) :Received intrathecal $3 \mathrm{ml}$ of $0.75 \%$ isobaric Ropivacaine with $0.5 \mathrm{ml}$ of normal saline.

All patients underwent a thorough pre-anesthetic check up. Complete hemogram, Blood sugar, Blood urea, Serum creatinine, Bleeding time, Clotting time and Urine examination were done in all. ECG and X-ray chest were advised in patients above $40 \mathrm{yrs}$ of age or if indicated.

Anesthetic plan was explained to all the patients. An informed written consent was obtained and the visual analogue score for pain assessment was explained. Tab Anxit $0.5 \mathrm{mg}$ was given to all on previous night \& Tab Ranitidine $150 \mathrm{mg}$ given orally at 6:00AM with sips of water on the day of surgery.

All the patients were kept nil by mouth overnight. After shifting the patient to operation theater a multipara vital monitor was attached and pre induction pulse rate, blood pressure, respiratory rate, oxygen saturation were recorded. Anesthetic trolley, anesthetic circuit and all the resuscitation equipment and drugs were checked \& kept ready.
A suitable wide bore Intravenous line was taken using $18 \mathrm{G}$ vein flow \& Intravenous Ringer lactate $10 \mathrm{ml} / \mathrm{kg}$ given 30 minutes prior to procedure.

All the patients were given sitting position. The back was prepared with an antiseptic solution and was drapped with a sterile wound towel. Intrathecal block given in $\mathrm{L}_{3}-\mathrm{L}_{4}$ space with 23 G Quincke's spinal needle.

After confirming the free flow of CSF, the drugs were administered according to groups of 30 patients each as follows:

\section{Group RD - Inj Isobaric Ropivacaine 0.75\% 3ml + Inj Dexmedetomidine $5 \mu \mathrm{g}(0.5 \mathrm{ml})$}

Group R -Inj. Isobaric Ropivacaine 0.75\% 3ml + Inj. Normal saline $0.5 \mathrm{ml}$

Total volume injected was 3.5 mlintrathecally in both the groups.

The patient were given supine position immediately after the spinal blockade \& various parameters of sensory block \& motor blocks were assessed.

\section{Dilution of Dexmedetomidine}

Each $1 \mathrm{ml}$ ampoule of Dexmedetomidine contains $100 \mu \mathrm{gm}$ of the drug.

- From this we took $0.1 \mathrm{ml}$, that is upto mark 0.1 drug in a tuberculin syringe.

- Then it was diluted upto Mark 1.0 ,that is total volume of $1 \mathrm{ml}$ by using Normal Saline under all aseptic and antiseptic precautions, making concentration to be $1 \mu \mathrm{gm}$ per $0.1 \mathrm{ml}$.

- After this $0.5 \mathrm{ml}$ of this drug, which contained $5 \mu \mathrm{gm}$ of Dexmedetomidine was transferred to a $5 \mathrm{ml}$ syringe which already contained $3 \mathrm{ml}$ of $0.75 \%$ isobaric Ropivacaine. Hence total $3.5 \mathrm{ml}$ volume of drug was made.

\section{Observations}

- Sensory block: was checked by using pin prick method

- Onset of sensory block ( Loss of sensation at the level of L1 dermatome)

- Highest sensory level (noted after 20 min of spinal blockade)

- Two segment regression of block

- Duration of sensory block (time interval from onset to when sensation felt at L1 dermatome again)

Motor block: was assessed by Bromage scale.

- Grade 0: no motor blockade

- Grade 1: unable to raise extended leg

- Grade 2: unable to flex knee

- Grade 3: unable to flex ankle

- Onset of motor block ( time to attain Bromage grade I)

- Time to achieve maximum Bromagegrade III

- Maximum Bromage grade (30 minutes) 


\section{International Journal of Science and Research (IJSR) \\ ISSN (Online): 2319-7064}

Index Copernicus Value (2013): 6.14 | Impact Factor (2014): 5.611

- Duration of motor block (time interval from onset to when Bromage grade become 0 again)

Intra operative Sedation score: Level of sedation was assessed by Ramsey Sedation Score.

1) Patient is anxious and agitated or restless or both

2) Patient is cooperative, oriented and tranquil

3) Patient responds to commands only

4) Patient exhibits brisk response to light glabellar tap or loud auditory stimulus

5) Patient exhibits sluggish response to light glabellar tap or loud auditory stimulus

6) Patient exhibits no response

\section{Vital parameters}

Vital parameters like Systolic Blood Pressure, Diastolic Blood Pressure, Pulse, $\mathrm{SpO}_{2}$, and Sedation Score were monitored. Recording of data was done before giving block and then at 2, 5, 10, $20 \& 30$ minutes after giving the block. Then every 15 minutes till the 1 hour and every 30 minutes till end of surgery.

Duration of surgery: was also noted

\section{Intra and post operative complications:}

Patients were monitored for various intra and post operative complications which are as follows:Bradycardia, Hypotension, Respiratory Depression, Nausea and Vomiting, High spinal, Shivering and Rigors, Excessive sedation, Dryness of Mouth, Headache, Backache, Retention of Urine, Neurological sequelae

\section{Post operative period:}

- Vital parameters: were recorded every hourly till 8hrs post operatively.

- Pain assessment:

It was done by using Visual Analogue Scale (VAS). It is a $10 \mathrm{~cm}$ scale graded from $0-10$ in such a way that 0 denotes no pain and 10 denote most excruciating pain. Patients were asked to mark the point on the scale that corresponded to their level of pain intensity at the time of observation.
012345678910
NO EXCRUCIATING
PAIN PAIN
1. - No Pain
2. 1-2 - Mild pain
3. 2-4- Moderate pain
4. 5-7 - Severe pain
5. $8-10-$ Worst pain

\section{Assessment of Analgesia}

- Done by observing the duration of Absolute analgesia\&duration of Effective analgesia.

- Time taken from intrathecal Injection of drug to first sensitivity of any pain at the site of surgery taken as an absolute analgesia

- Time taken from intrathecal injection of drug to first rescue analgesia at VAS -4 taken as an effective analgesia.

\section{Rescue Analgesia}

- When VAS was $\geq 4$, Inj., Diclofenac Sodium $75 \mathrm{mg}$ was given intramuscularly as rescue analgesia and repeated again, if the patient complained of pain in next 24 hours. The total no. of doses of rescue analgesic required in 24 hours was compared in both the groups.

\section{Observations and Results}

A master chart was prepared to arrange the observed parameters of each and every case. Mean and standard values were taken out. Analysis of variance (ANOVA) of the data for the various parameters was done using student's paired t-test for intra group comparison and unpaired t-test for intergroup comparison. Mean duration of surgery in both the groups were also comparable being $102.83 \pm 31.61$ (minutes) in group $\mathrm{R} \quad \&$ $110.83 \pm 18.33$ (minutes) in group RD.

\section{Types of Surgeries Performed in Both the Groups}

\begin{tabular}{|c|c|c|c|c|}
\hline Type of Surgeries & Group R & $\%$ & Group RD & $\%$ \\
\hline Femur Enders & 3 & $10 \%$ & 1 & $3.33 \%$ \\
\hline Proximal Femur Nailing & 8 & $26.6 \%$ & 6 & $20 \%$ \\
\hline Dynamic Hip Screw & 7 & $23.3 \%$ & 8 & $26.6 \%$ \\
\hline Femur Inter Locking & 7 & $23.3 \%$ & 11 & $36.6 \%$ \\
\hline CC Screw Fixation & 1 & $3.33 \%$ & 2 & $6.66 \%$ \\
\hline Femur Plating & 2 & $6.66 \%$ & 1 & $3.33 \%$ \\
\hline Implant Extraction & 2 & $6.66 \%$ & 1 & $3.33 \%$ \\
\hline
\end{tabular}

\section{Comparison of changes in heart rate and blood pressure} in study groups:

The mean pre operative pulse rate being $(85.93 \pm 10.3)$ per minutes in Group R and (85.86 \pm 6.12$)$ per minutes in Group $\mathrm{RD}$, the mean systolic Blood Pressure being (124.73 \pm 12.42$)$ $\mathrm{mmHg}$ in Group R and (128.86 \pm 7.09$) \mathrm{mmHg}$ in Group RD, the mean diastolic Blood Pressure being (79.86 \pm 6.98$)$ $\mathrm{mmHg}$ in Group $\mathrm{R}$ and $(82.26 \pm 5.52) \mathrm{mmHg}$ in Group RD, were comparable in both the groups. 


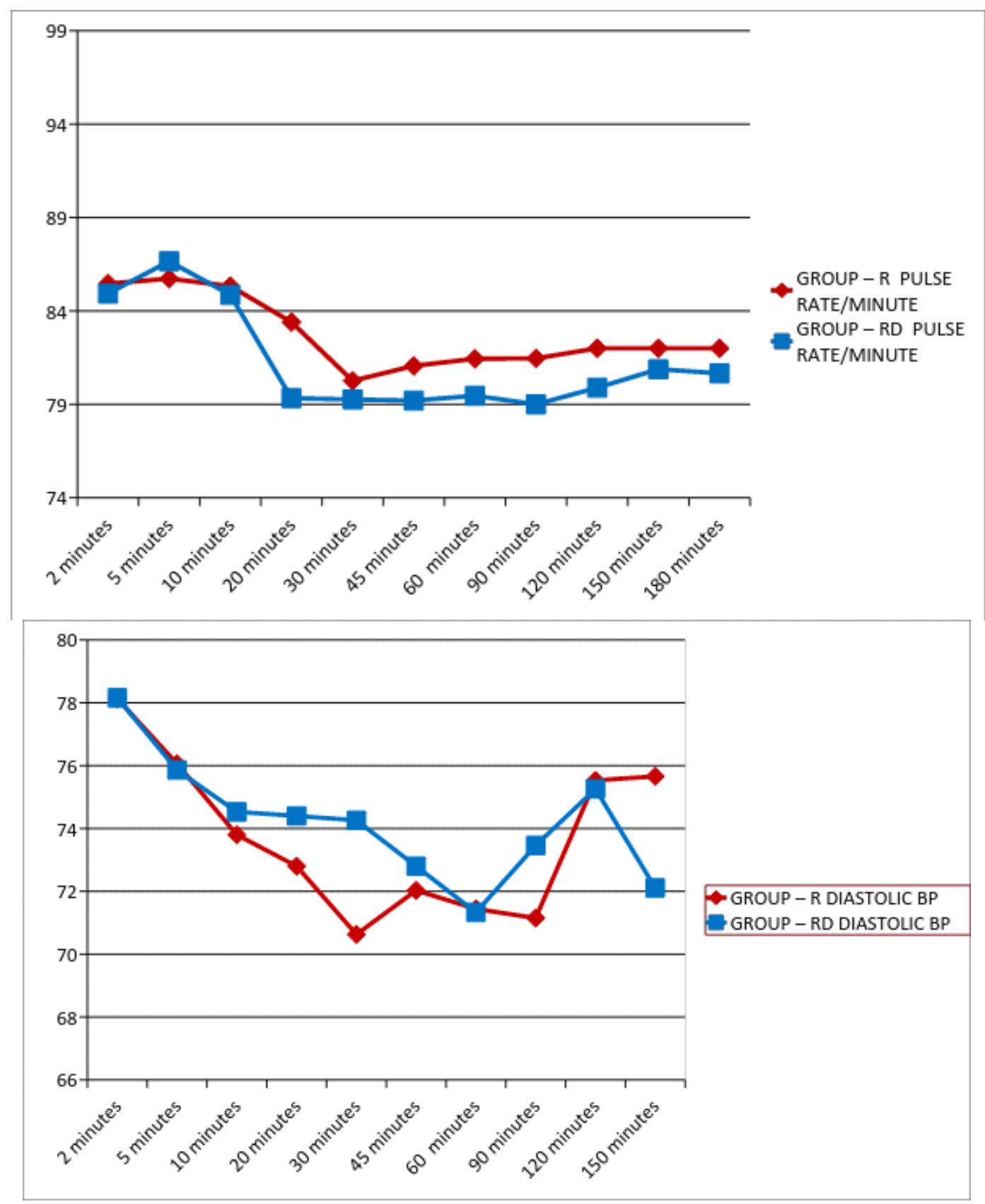

Comparison of changes in the duration of sensory blockade :

Duration of sensory block was measured by regression time to L-1 Level, It was $\mathbf{1 5 8 . 1 6} \pm \mathbf{2 3 . 0 6}$ minutes in Group $\mathrm{R}$, whereas it was210.16 $\pm \mathbf{3 6 . 1 3}$ minutes in Group RD. Thus it was prolonged in group RD as compared to group $\mathrm{R}$ and the difference was statistically highly significant. 


\section{International Journal of Science and Research (IJSR) \\ ISSN (Online): 2319-7064}

Index Copernicus Value (2013): 6.14 | Impact Factor (2014): 5.611

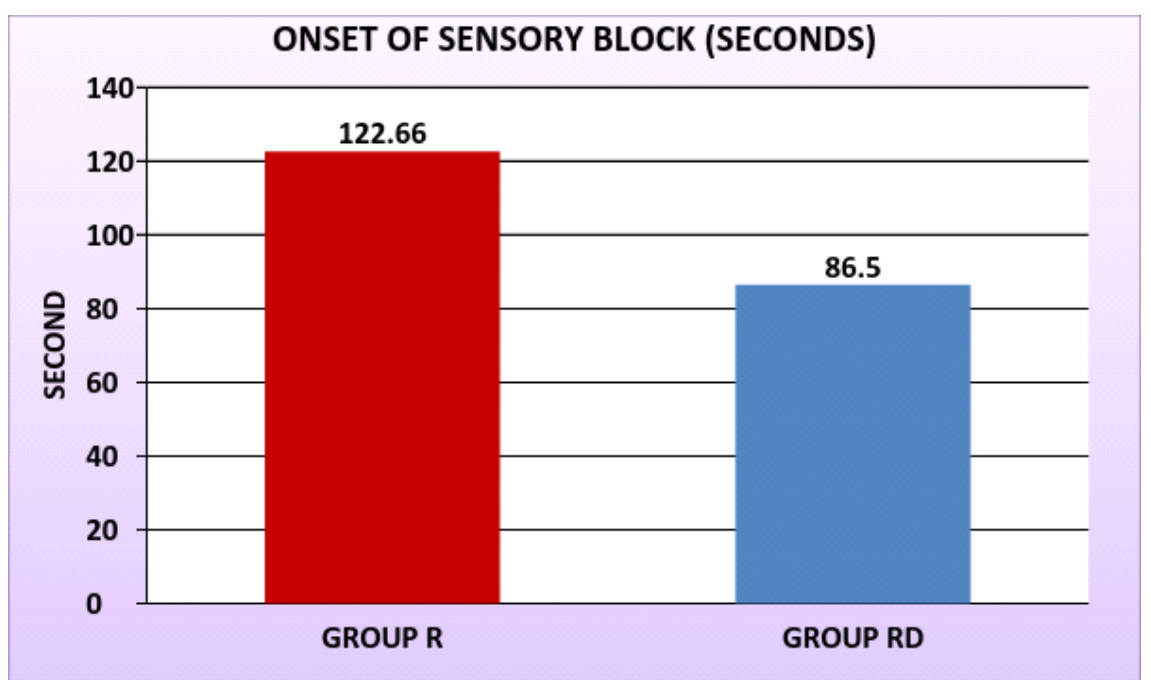

Comparison of changes in the motor blockade:

The Duration of motor block was taken when Bromage grade became 0. It was $\mathbf{1 8 8 . 8 3} \pm \mathbf{2 5 . 6 5}$ minutes in Group R, while it was $\mathbf{2 5 6 . 3 3} \pm \mathbf{3 6 . 0 5}$ minutes in Group RD. So it was prolonged in group $\mathrm{RD}$ compared to group $\mathrm{R}$ and the difference was statistically highly significant.

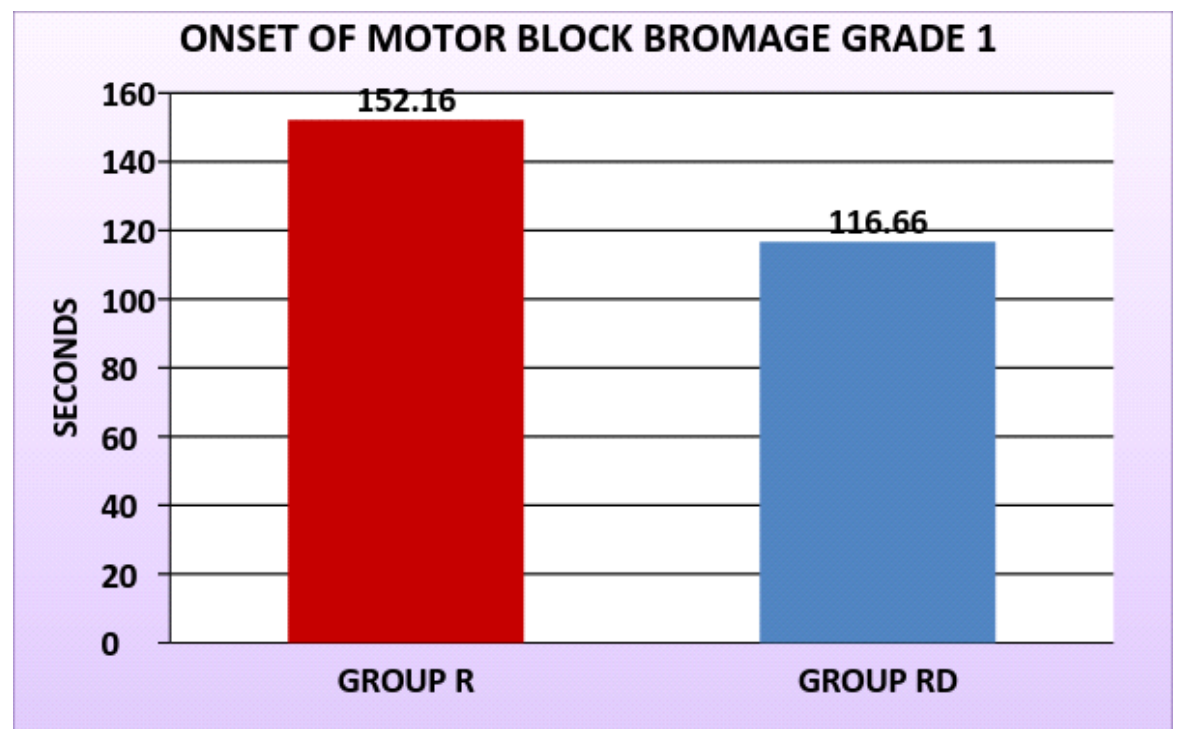

Inter group comparison by applying ANOVA, showed no statistically significant change in pulse rate, systolic, diastolic bloodpressure and oxygen saturation during intraoperative and postoperative periods among both the groups.
Comparison of Sedation score of the patients of both the groups.

$93.33 \%$ of patients in Group $\mathrm{R}$ had sedation score 2 (cooperative, oriented and tranquil) and $6.66 \%$ patients had score 3 (responding to command only) whereas in Group RD $10 \%$ of the patients had sedation score 2 and $90 \%$ of the patients had sedation score 3 . 
International Journal of Science and Research (IJSR)

ISSN (Online): 2319-7064

Index Copernicus Value (2013): 6.14 | Impact Factor (2014): 5.611

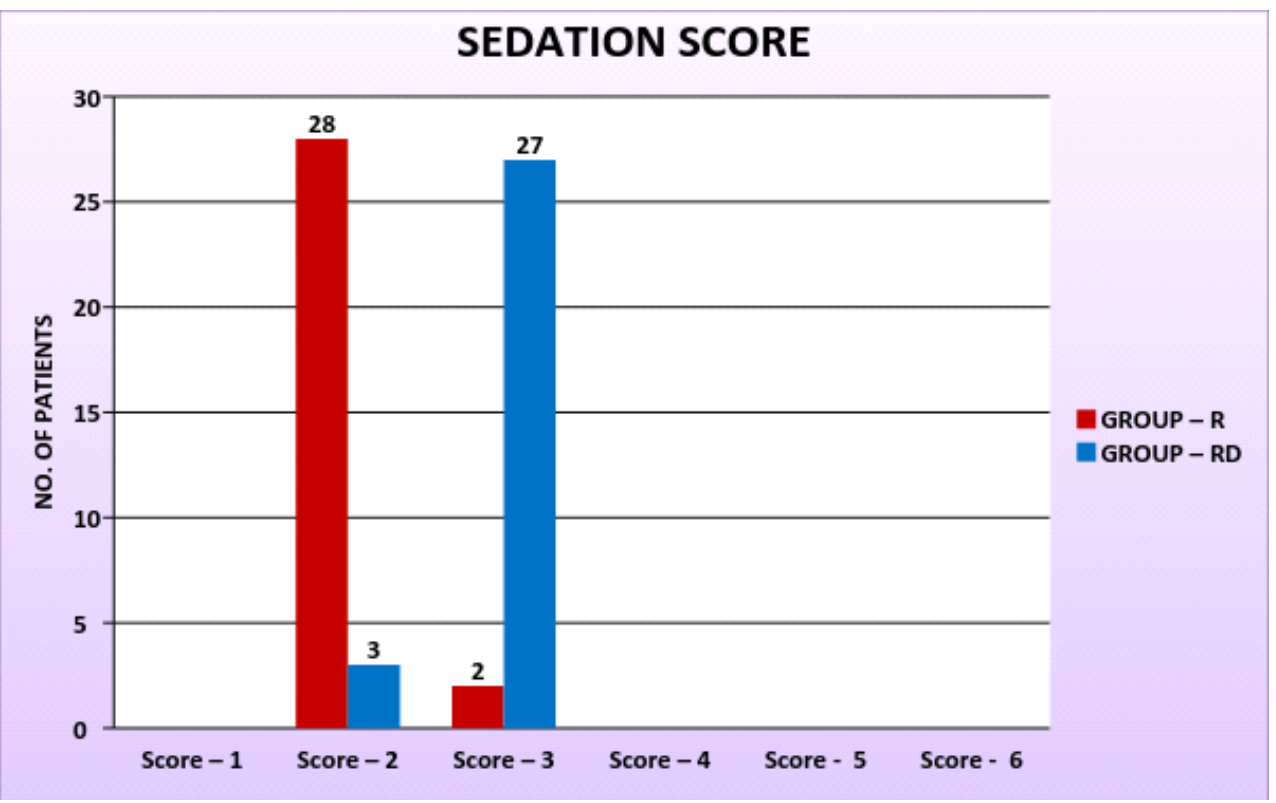

Comparison of duration of absolute analgesia:

The duration of absolute analgesia in Group $\mathrm{R}$ was $215.03 \pm 25.57$ minutes, while in group $\mathrm{RD}$, it was
$350.33 \pm 59.49$ minutes. So the duration of absolute analgesia was prolonged in group $\mathrm{RD}$ than in group $\mathrm{R}$ and difference wasstatistically highly significant.

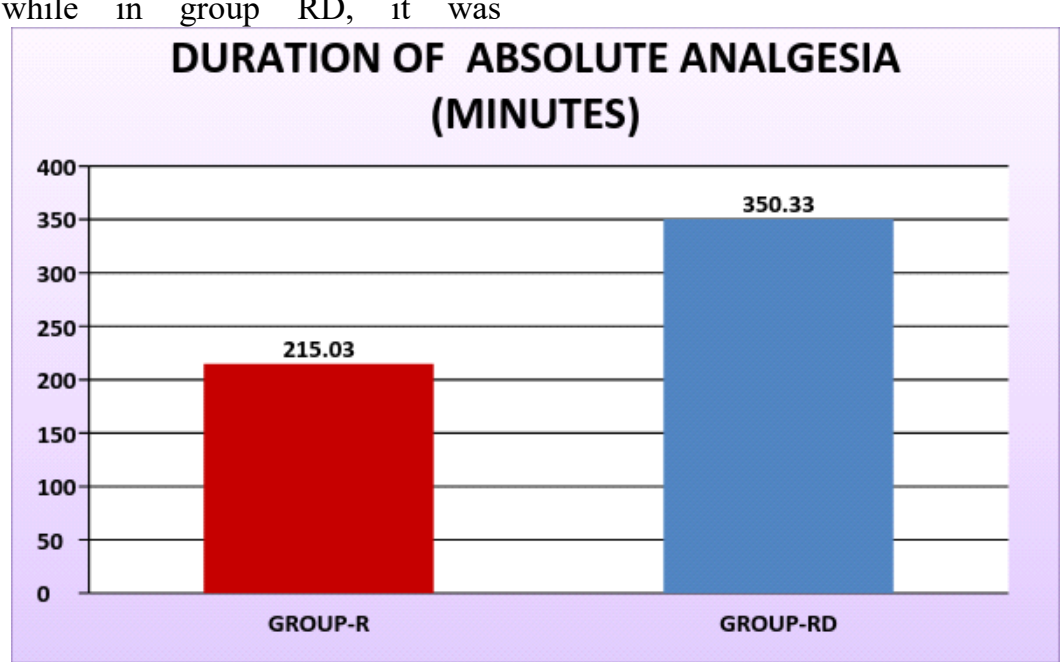

Comparison of duration of effective analgesia :

The duration of effective analgesia in Group $\mathrm{R}$ was $271.83 \pm 34.42$ minutes, while in group $\mathrm{RD}$, it was
$490.83 \pm 38.73$ minutes. So the duration of effective analgesia was prolonged in group RD than in group R and difference was statistically highly significant.

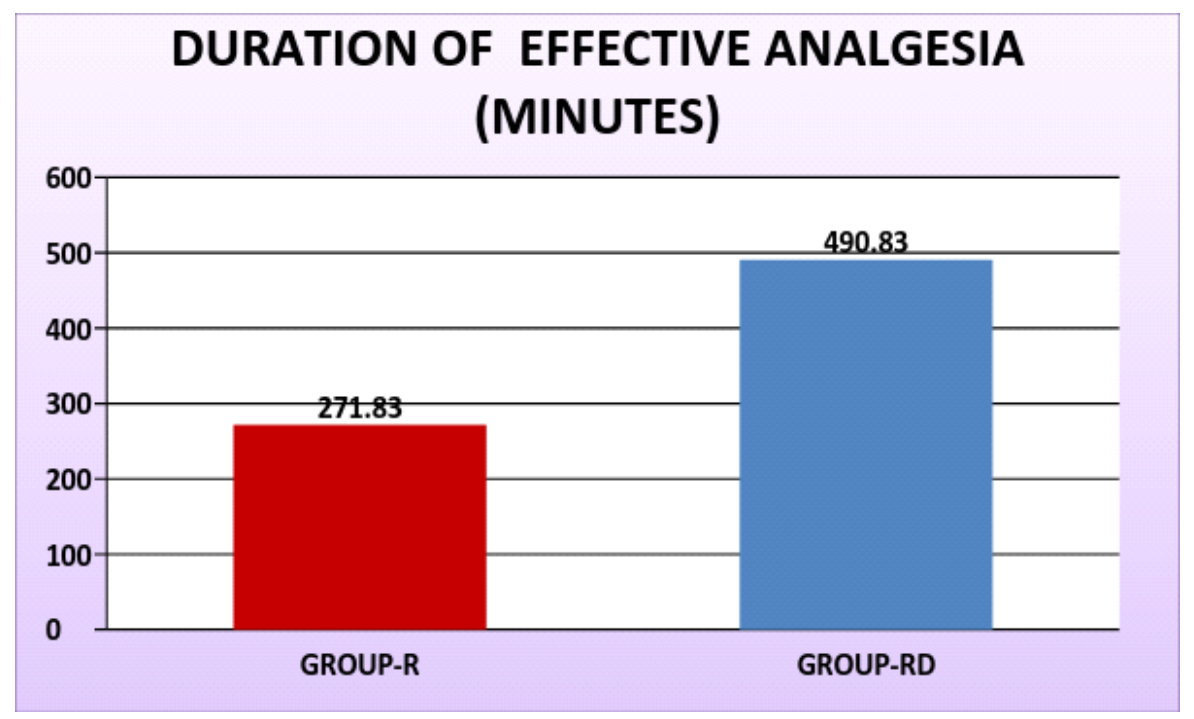

Volume 5 Issue 2, February 2016

www.ijsr.net 


\section{International Journal of Science and Research (IJSR) \\ ISSN (Online): 2319-7064 \\ Index Copernicus Value (2013): 6.14 | Impact Factor (2014): 5.611}

Comparison of the number of rescue analgesics :

The no.ofrescue analgesics given to the patient were,

$2.53 \pm 0.77$ in Group $\mathrm{R}$ as compared to $1.6 \pm 0.49$ in Group RD $(\mathrm{p}<0.001)$ during $24 \mathrm{hr}$ period and the difference was statistically highly significant.

NO. OF RESCUE ANALGESICS (IN 24 HOURS)

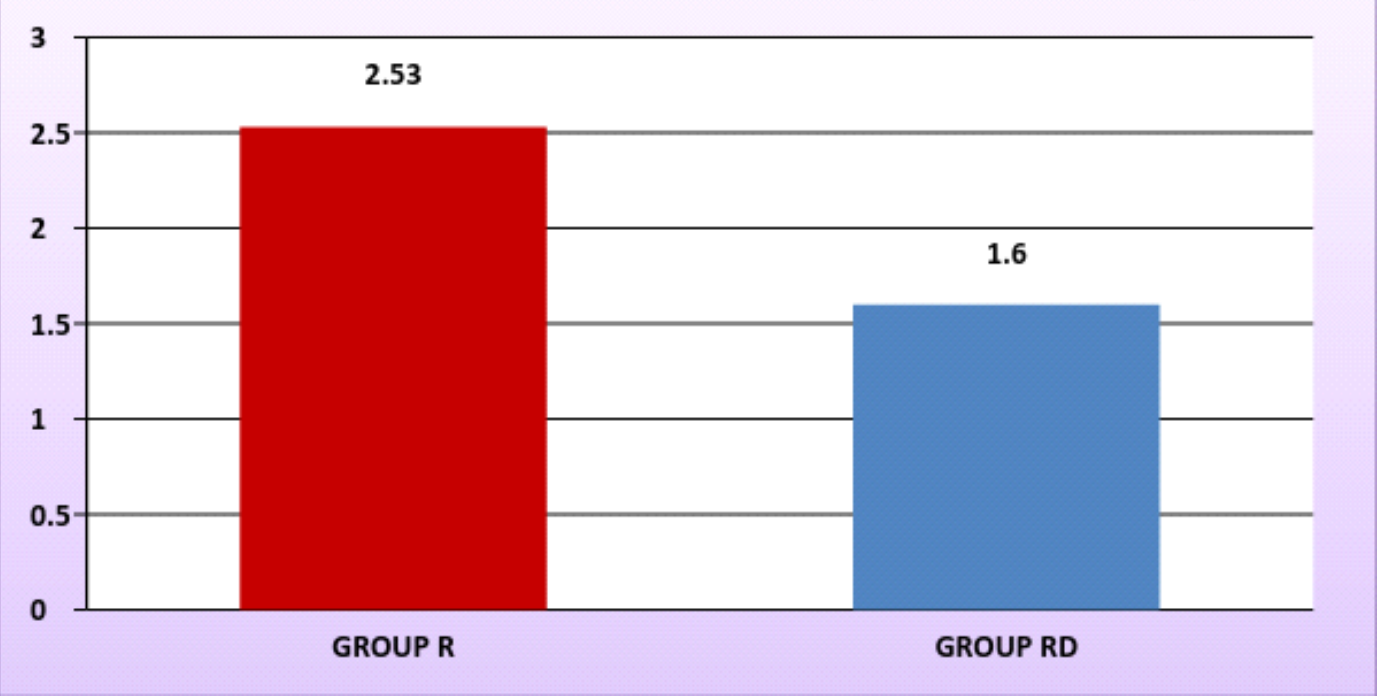

\section{Comparison of the intra-op Complications}

In the Group R, 1 patient's (3.33\%) had hypotension, whereas in Group RD 4 patients (13.33\%) had hypotension. No other intra operative complications were observed in both the groups.
No patients had any complication like bradycardia, hypotension, nausea/vomiting, retention of urine and neurological sequel in the postoperative period in either of the groups.

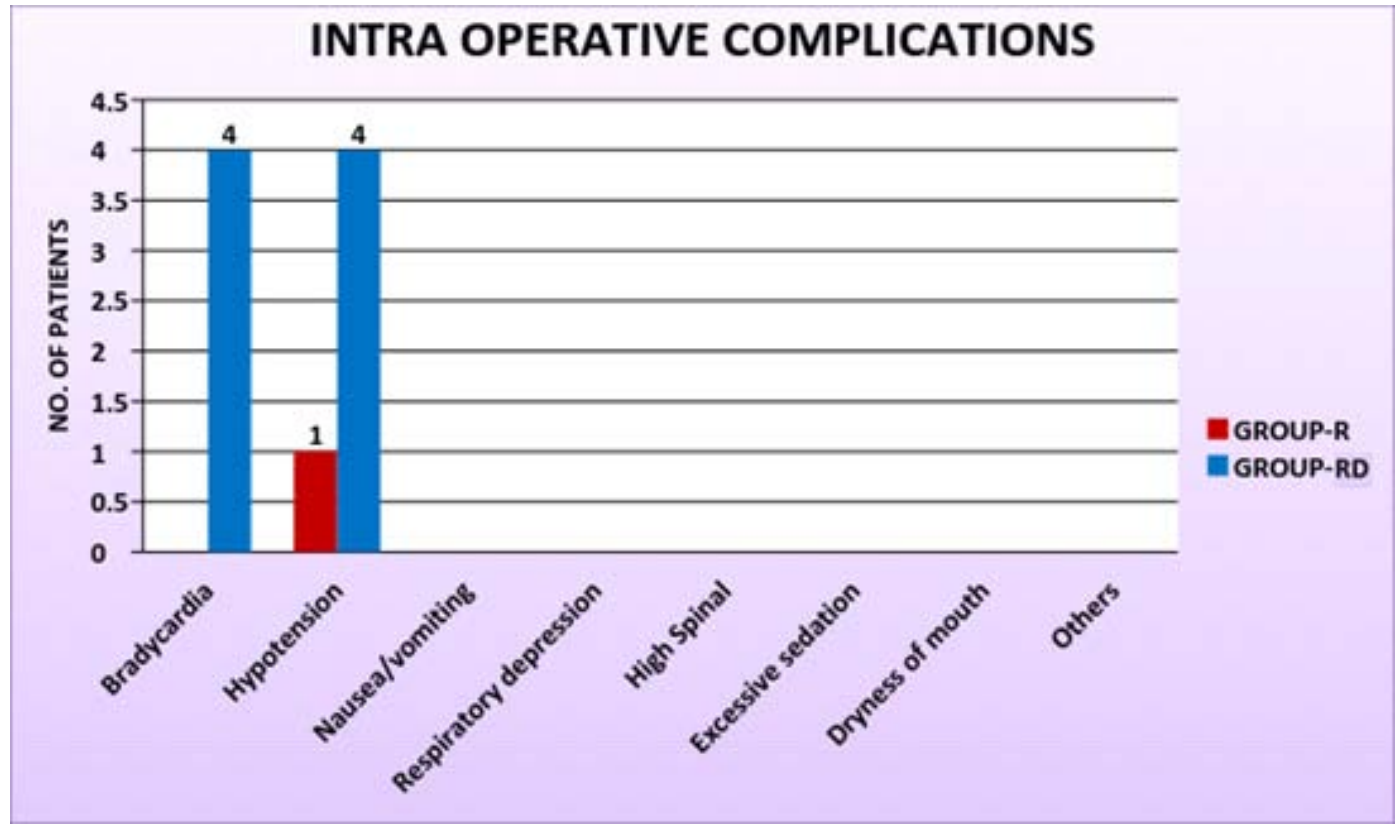

\section{Summary}

The study consisted of 60 patients of ASA status I and II undergoing lower limb orthopedic surgeries. Patients were randomly allotted into 2 groups of 30 patients each. Patients were monitored for various parameters like sensory block, motor block, pulse rate, blood pressure, oxygen saturation, sedation score, duration of analgesia and intra and postoperative complications.
The mean time of onset of sensory block, time taken for two segment regression, Onset of motor block, both absolute and effective analgesia durations were prolonged in Group RD

Intraoperatively there were no complications except that 1 patient in Group $\mathrm{R}$ and 4 patients in Group RD developed hypotension which responded to bolus dose of intravenous fluids and intravenous inj. Mephentermine $5 \mathrm{mg}$ increments while 4 patients in Group RD had bradycardia for which inj. atropine $0.6 \mathrm{mg}$ iv was given. 


\section{International Journal of Science and Research (IJSR) \\ ISSN (Online): 2319-7064}

Index Copernicus Value (2013): 6.14 | Impact Factor (2014): 5.611

No postoperative complications were seen in either of the groups.

\section{Conclusion}

After going through the study results and comparing the effect of addition of Dexmedetomidine $(5 \mu \mathrm{g})$ to intrathecal isobaric Ropivacaine $(0.75 \%)$ with isobaric Ropivacaine $(0.75 \%)$ alone, following conclusions can be drawn:

1) It quickens the onset and prolongs the duration of sensory block.

2) Onset and time to achieve maximum motor block is fastened and duration of motor block is prolonged.

3) It provides stable hemodynamics with minor fluctuations in blood pressure and heart rate.

4) Provides sedation without causing respiratory depression and does not affect oxygen saturation.

5) Duration of absolute and effective analgesia is significantly prolonged. The number of rescue analgesics required in postoperative period is also significantly reduced.

6) It does not increase the incidences of complications in intra and post operative period.

Thus, mixture of Dexmedetomidine $5 \mu \mathrm{g}$ and Isobaric Ropivacaine $0.75 \%(22.5 \mathrm{mg})$ when given intrathecally influences the sensory and motor block by shortening the onset time and prolonging the duration of absolute and effective analgesia without affecting the other parameters and complications of subarachnoid block.

\section{References}

[1] Rajni Gupta, Jaishri Bogra, Reetu Verma, Monica Kohli, Jitendra Kumar Kushwaha, and Sanjiv KumarDexmedetomidine as an intrathecal adjuvant for postoperative analgesia- Indian J Anaesth. 2011 Jul-Aug; 55(4): 347-351.

[2] Alka Shah, Ila Patel, Rachana Gandhi- Haemodynamic effects of intrathecal dexmedetomidine added to ropivacaine intraoperatively and for postoperative analgesia- International Journal of Basic \& Clinical Pharmacology | January-February 2013 | Vol 2 | Issue 1 Page 26.

[3] Marie-Pier Malenfant Rancourt ,MD, Natalie T. Albert, MD, FRCPC, Maxime Côté, MD, FRCPC, Dany-R Létourneau, MD, FRCPC and Paul-Marie Bernard, MScPosterior Tibial Nerve Sensory Blockade Duration Prolonged by Adding Dexmedetomidine to RopivacaineA \& A October 2012 vol. 115 no. 4 958-962.

[4] Beom Gyu Kim, Hyun Kang- The Effect of Preemptive Perianal Ropivacaine and Ropivacaine with Dexmedetomidine on Pain after Hemorrhoidectomy: A Prospective, Randomized, Double-Blind, PlaceboControlled Study- Indian Journal of Surgery,12th June 2012,10.1007/s12262-012-0622-5.

[5] Sukhminder Jit Singh Bajwa, Sukhwinder Kaur Bajwa, Jasbir Kaur, Gurpreet Singh, Vikramjit Arora, Sachin Gupta, Ashish Kulshrestha, Amarjit Singh, SS Parmar, Anita Singh, and SPS Goraya1-dexmedetomidine and clonidine in epidural anaesthesia : a comparative evaluation- Indian J Anaesth. 2011 Mar-Apr; 55(2): 116121.
[6] Sandip Sinha, MD, Maitreyee Mukherjee, MD, Sajib Chatterjee, MS, Mukesh K Vijay, MS, MCH,Abhijit Hazra, MD, Manjushree Ray, MD- Comparative study of analgesic efficacy of ropivacaine with ropivacaine plus dexmedetomidine for paravertebral block in unilateral renal surgery- An International Journal of Anesthesiology, Pain Management, Intensive Care \& Resuscitation, 2012;16(1):38-42.

[7] Vijay G Anand, M Kannan, A Thavamani, and Merlin J Bridgit- Effects of dexmedetomidine added to caudal ropivacaine in paediatric lower abdominal surgeriesIndian J Anaesth. 2011 Jul-Aug; 55(4): 340-346.

[8] Chad M. Brummett, M.D., Elizabeth K. Hong, B.S., Allison M. Janda, B.A., Francesco S. Amodeo, B.S., and Ralph Lydic, Ph.D. - Perineural Dexmedetomidine Added to Ropivacaine for Sciatic Nerve Block in Rats Prolongs the Duration of Analgesia by Blocking the Hyperpolarization- activated Cation CurrentAnesthesiology. 2011 October; 115(4): 836-843.

[9] Dr. Ravindra. S. Giri,Dr. Mohammed Mukarram Iqbal, Dr Zainab Ghazala- A Randomized Clinical Trial Comparing the Efficacy and Safety of Ropivacaine $0.75 \%$ Alone and in Combination with Dexmedetomidine for Lower Abdominal and Lower Limb Surgeries- VCFL Sciences Journal/ ISSN: 22319522 Vol. 3 Issue. 2

\section{Author Profile}

Dr Malathi C N, currently working as Professor in Anesthesiology in JSS medical college and hospital, Mysuru, Karnataka, India. She has received MBBS degree from KIMS, Hubli, Karnataka. DA from KMC, mangalore and MD from JSS medical college and hospital, Mysuru, Karnataka.Shehas also published research papers in national and international journals.

Dr Athyun Gajula, received MBBS degree from Chalmeda Anand Rao Institute of medical sciences, Telangana state , India. He is working as a junior residen in the department of anesthesiology, JSS Medical College, Mysuru, Karnataka, India. 